\title{
The Effects of Repetitive Sit-to-Stand Training with a Paretic- side Asymmetrical Foot Position on the Balance of Chronic Stroke Subjects
}

\author{
Jae Hyo Park', Young Mi Kim², Na Kyung Lee ${ }^{2}$ \\ 'Department of Physical Therapy, College of Biomedical Science, Daegu Haany University; ${ }^{2}$ Department of Rehabilitation Science, Graduate School, \\ Daegu University, Gyeongsan, Korea
}

Purpose: This study aimed to improve the asymmetrical weight-bearing ratio, by applying different repetitive sit-to-stand training methods to the paretic-side foot of hemiplegic patients, as well as to provide the necessary information for applying balance training with hemiplegic patients.

Methods: The subjects were divided into two groups: a spontaneous foot group and an asymmetrical foot group. They all performed repetitive sit-to-stand training five times a week for a total of six weeks. The sit-to-standing movement was studied using standardized clinical tests. The Biodex Balance System, Time up and go test (TUG), 5 times sit-to-stand test (5XSST), and functional reach test (FRT) were used to measure the static and dynamic standing balance of the patients.

Results: In the balance system measurement, the results for the overall index, ant-post index, med-lat index, fall risk index, 5XSST, and FRT after the training differed significantly between the comparison groups $(p<0.05)$. In the evaluation of dynamic balance, the differences in TUG did not differ significantly between the comparison groups after the training ( $p>0.05)$.

Conclusion: The study found that the asymmetrical group showed significant increases in static and dynamic balance in comparison to the spontaneous group after repetitive sit-to-stand training. Based on this result, it is clear that training in an asymmetrical position with the paretic foot back can increase the left-right stability limit and the anterior-posterior stability limit, thus improving balance control.

Keywords: Stroke, Sit-to-stand, Balance, Asymmetrical foot position

\section{INTRODUCTION}

Stroke is a disease accompanied by various symptoms with ischemic or vascular causes in the brain blood vessels. ${ }^{1}$ One of the most common symptoms after stroke is weakness on the paralyzed side, which is caused by an imbalance in muscle strength; as a result, patients with hemiplegia have asymmetric weight bearing on one side, which exacerbates their balance problems. ${ }^{2}$ Difficulties in controlling balance can lead to numerous problems in activities of daily living. ${ }^{3}$

As a result, the asymmetrical posture turn out when performing movements, such as walking, sitting, and standing, leads to in-

Received May 30, 2015 Revised Jun 18, 2015

Accepted Jun 18, 2015

Corresponding author Young Mi Kim

E-mail h1015m@naver.com creased weight-bearing for the non-paretic leg over the paretic leg.,5 Because of this imbalance in the weight-bearing pattern, it becomes difficult to control balance in the standing posture. ${ }^{6,7}$ Balance control has been reported as a key factor in predicting participation in rehabilitation program, the extent of recovery, and the ability to live an independent life. ${ }^{8}$ The hemiplegic patients have a sit-to-stand characterized by a longer duration, ${ }^{9,10}$ changes to both the anterior/ posterior and medial/lateral displacement of the center of gravity in comparison with a normal person, ${ }^{11}$ and an asymmetrical weightbearing pattern. ${ }^{12}$ The asymmetrical weight-bearing pattern in individuals with hemiparesis can be worsened by changing the initial foot position of the unaffected leg during sit-to-stand. ${ }^{13}$ Therefore,

Copylight (C2015 The Korea Society of Physical Therapy

This is an Open Access article distribute under the terms of the Creative Commons Attribution Non-commercial License (Http:// creativecommons.org/license/by-nc/3.o.) which permits unrestricted non-commercial use, distribution, and reproduction in any medium, provided the original work is properly cited. 
the most common characteristic of the hemiplegia due to stroke is the imbalance between the paretic and non-paretic limbs, which limited activities of daily living. Thus, hemiplegic patients should perform sit-to-stand training to improve their ability to walk independently and to return to their activities of daily living.

Practicing sit-to-stand movements by utilizing strategies that facilitate weight bearing on the affected leg can provide benefits, improving functional movements, preventing falls, and counteracting the learned non-use of the limb. ${ }^{13,14}$

Thus, this study aimed to identify ways to improve the asymmetrical weight-bearing ratio by applying different repetitive sit-tostand training to the non-paretic foot of hemiplegic patients, as well as to provide the necessary information for applying balance training with hemiplegic patients.

\section{METHODS}

\section{Subjects}

A total of 23 patients were admitted to the Inpatient Stroke Unit of P Rehabilitation Hospital. There were no significant differences in the height, weight, age, time since stroke, etc. The mean ( \pm standard deviation) height, weight, age, and time since stroke in the Spontaneous group were $161.4 \pm 8.5 \mathrm{~cm}, 61.2 \pm 13.1 \mathrm{~kg}, 61.3 \pm 10.8$ years, and $33.4 \pm 21.1$ months, respectively. The mean ( \pm standard deviation) height, weight, age, and time since stroke in the Aasymmetrical group were $163.3 \pm 8.2 \mathrm{~cm}, 61.4 \pm 9.9 \mathrm{~kg}, 64.3 \pm 7.1$ years, and $30 \pm$ 16.9 months, respectively.

The subject inclusion criteria were as follows: more than six months after the injury, the ability to walk $10 \mathrm{~m}$ independently without aid, and the ability to rise from a chair without the use of the hands and with the non-paretic lower limb supported on a step. All the patients had a Modified Ashworth Scale (MAS) score of below two-grade spasticity and a Mini Mental State Examination (MMSE) score of 24 or higher. Individuals were excluded if they had less than $15^{\circ}$ of passive ankle dorsiflexion, an orthopedic disorder that could interfere with the experiment, neglect of space on the affected side, or any other neurologic disease or auditory or visual deficit that could prevent data collection. The University Research Ethics Board approved the study protocol, and all the subjects gave their informed consent. The experiment subjects underwent neurologic physical therapy five times a week under a physical therapist with more than three years of experience, and they were divided into two groups-a spontaneous group and a asymmetrical group -that also underwent repetitive sit-to-stand training five times a week for a total of six weeks.

\section{Experimental methods}

1) Measurement

\section{(1) Balance system}

For the evaluation of the balance position, the Biodex Balance System SD (Biodex Medical System, Inc., USA) was used. The test was run for 20 seconds, and the test application levels of the mat were $1-8$, wherein 1 was the most common movement, and 8 was the least common movement. Because patients with central nervous system injuries were targeted in this study, the test was conducted at the lowest level, 8 , which had the most minimal movement and the lowest risk factor. The balance ability was provided as the balance index, and the better the balance ability, the lower the balance index appeared to be. The assessment program measured the postural stability test (PST) and the limits of stability test (LST). Before the test, the patient stood on a fixed mat on both feet and exercised three times to adjust to the equipment, after which the test was started. The subjects were measured in a position in which their feet were comfortably opened and both hands were on the equipment. Three measurements were performed, and the results were averaged.

\section{(2) Time up and go test (TUG)}

This is a simple way to assess standing ability and movement ability. The patient sits on a chair with arm rests, and once the tester signals the patient, the time it takes the patient to stand up, walk for $3 \mathrm{~m}$, pass the turning point, and return to the chair is measured. The intraclass correlation was 0.99 , and the interclass correlation was 0.98 . These have been reported as high levels of confidence. ${ }^{15}$ In recent years, this method has been used to evaluate the balance ability and functional movement of the elderly and the fragile elderly, as well as stroke, Parkinson's disease, and arthritic disease patients, in order to predict their risk of a fall. ${ }^{16}$

\section{(3) 5 times sit-to-stand test (5XSST)}

To measure leg strength, the 5XSST was used. This test measures the time required to assume the sit-to-stand position on a stool five times without using the hands. The interclass correlation was $0.87 .^{17}$ 


\section{(4) Functional reach test (FRT)}

To measure balance ability, the FRT was used, and the maximum reach distance was measured. The ability of standing subjects to reach horizontally forward with the left hand $\left(90^{\circ}\right.$ of shoulder flexion and a straight arm) while maintaining a fixed base of support was examined. The instructions provided were similar to those provided by Duncan et al. ${ }^{18}$ A $150 \mathrm{~cm}$ yardstick was horizontally mounted on the wall at the height of the acromion. The reach distance was measured as the displacement of the finger between the initial position and the end position. In accordance with Duncan et al., the reaching strategy was not otherwise controlled for.

\section{Intervention}

The stand-up training was performed according to the studies of Roy $^{19}$ and Rocha Ade. ${ }^{20}$ It was divided according to the following two terms, taking into account the conditions of use and the fatigue of the patients.

1) Spontaneous (SPO): No instructions were given regarding the initial position of the feet.

2) Asymmetrical (ASY): The paretic foot was placed back, with $15^{\circ}$ of ankle dorsiflexion, and positioned behind the unaffected foot at a distance corresponding to $50 \%$ of the subject's foot length, while the non-paretic foot is kept to the front with $0^{\circ}$ of ankle dorsiflexion and $90^{\circ}$ of knee flexion.

The configuration of the training is as follows:

(1) Move the cup from the non-paretic side to the paretic side while sitting 10 times.

(2) Carry out the sit-to-stand movement 10 times, aligning the body to the center by looking at a mirror in front.

(3) Carry out the sit-to-stand movement 10 times while picking up the small blocks in front of the paretic foot with the non-paretic hand.

(4) Carry out the sit-to-stand movement 10 times while putting the weight on the paretic side with the aid of a therapist.

(5) Carry out the sit-to-stand movement 10 times, as directed by the therapist, without looking in the mirror. In all the training sets, a one-minute rest was allowed after each set. Considering the intensity of the training, 12-times sit-to-stand training was conducted in weeks 3 and 4, and 15 times sit-to-stand training was conducted in weeks 5 and 6 .

\section{Statistical analysis}

The descriptive statistics, tests for normality (Shapiro-Wilk Test), and homogeneity of variance were calculated as the outcome variables using SPSS 20.0 software for Windows. An independent twosample t-test was used because of the homogeneity of the subjects, and the differences before and after the training were calculated and compared using an independent two-sample t-test. The statistical significance level was set at $\alpha=0.05$.

\section{RESULTS}

\section{A comparison of the balance before and after the training on} each group

Overall index increased from $1.07 \pm 0.72$ to $1.14 \pm 0.58$ in spontaneous group and decreased from $1.78 \pm 1.12$ to $1.14 \pm 0.75$ in asymmetrical group. Ant-post index decreased from $0.80 \pm 0.60$ to $0.71 \pm 0.46$ in spontaneous group and decreased from $1.21 \pm 0.91$ to $0.66 \pm 0.46$ in asymmetrical group. Med-lat index increased from $0.59 \pm 0.53$ to $0.71 \pm 0.48$ in spontaneous group and decreased from $1.05 \pm 0.79$ to $0.64 \pm 0.65$ in asymmetrical group. Fall risk index decreased from $3.18 \pm 1.39$ to $3.00 \pm 1.34$ in spontaneous group and decreased from $4.68 \pm 2.11$ to $2.86 \pm 1.05$ in asymmetrical group. 5XSST index decreased from $16.89 \pm 4.28$ to $16.54 \pm 5.09$ in spontaneous group and decreased from $20.06 \pm 5.42$ to $16.53 \pm 5.51$ in asymmetrical group. FRT index increased from $19.36 \pm 6.42$ to $23.43 \pm 3.85$ in spontaneous group and increased from $14.91 \pm 6.11$ to $21.81 \pm 4.59$ in asymmetrical group. In the balance system measurement, the results for the overall index, ant-post index, med-lat index, fall risk index 5XSST and FRT after the training differed significantly between the comparison groups $(\mathrm{p}<0.05)$.

TUG index increased from $20.81 \pm 9.95$ to $21.24 \pm 12.58$ in spontaneous group and decreased from $21.29 \pm 11.02$ to $19.91 \pm 10.26$ in asymmetrical group. In the evaluation of dynamic balance, the differences in TUG did not differ significantly between the comparison groups after the training $(\mathrm{p}>0.05)$. Table was showed the balance of the subjects in the text (Table 1).

\section{DISCUSSION}

Thus, this study aimed to identify ways to improve the asymmetrical weight-bearing ratio by applying different types of repetitive sit- 
Table 1. A comparison of balance before and after training in each group

\begin{tabular}{|c|c|c|c|c|c|c|c|}
\hline & & \multicolumn{2}{|c|}{ SPO group $^{+}(n=11)$} & \multicolumn{2}{|c|}{ ASY group ${ }^{*}(n=12)$} & \multirow{2}{*}{$\mathrm{t}$} & \multirow{2}{*}{$p$} \\
\hline & & Pre-test & Post-test & Pre-test & Post-test & & \\
\hline \multirow[t]{4}{*}{ Balance system } & Overall & $1.07 \pm 0.72$ & $1.14 \pm 0.58$ & $1.78 \pm 1.12$ & $1.14 \pm 0.75$ & 3.162 & $0.004^{*}$ \\
\hline & Ant-post & $0.80 \pm 0.60$ & $0.71 \pm 0.46$ & $1.21 \pm 0.91$ & $0.66 \pm 0.46$ & 2.108 & $0.045^{*}$ \\
\hline & Med-lat & $0.59 \pm 0.53$ & $0.71 \pm 0.48$ & $1.05 \pm 0.79$ & $0.64 \pm 0.65$ & 3.046 & $0.005^{*}$ \\
\hline & Fall risk & $3.18 \pm 1.39$ & $3.00 \pm 1.34$ & $4.68 \pm 2.11$ & $2.86 \pm 1.05$ & 2.300 & $0.037^{*}$ \\
\hline TUG & & $20.81 \pm 9.95$ & $21.24 \pm 12.58$ & $21.29 \pm 11.02$ & $19.91 \pm 10.26$ & 1.413 & 0.173 \\
\hline 5XSST & & $16.89 \pm 4.28$ & $16.54 \pm 5.09$ & $20.06 \pm 5.42$ & $16.53 \pm 5.51$ & 2.386 & $0.024^{*}$ \\
\hline FRT & & $19.36 \pm 6.42$ & $23.43 \pm 3.85$ & $14.91 \pm 6.11$ & $21.81 \pm 4.59$ & -2.287 & $0.034^{*}$ \\
\hline
\end{tabular}

${ }^{*} p<0.05$; SPO group, Spontaneous foot group; ${ }^{*}$ ASY group, Asymmetrical foot group.

to-stand training to the non-paretic foot of hemiplegic patients, as well as to provide the necessary information for applying balance training with hemiplegic patients. The results of our study indicate that all indexes (overall, ant-post, med-lat, and fall risk) for the asymmetrical foot group improved following training. The asymmetrical foot group also showed improvements after training in the 5XSST and FRT, though not in the TUG.

The posterior foot placement was shown to be influential. Positioning the foot further back enabled lower maximum mean extension moments at the hip $(148.8 \mathrm{~N} \cdot \mathrm{m}$ versus $32.7 \mathrm{~N} \cdot \mathrm{m}$ ) to be used for the sit-to-stand movement. ${ }^{21}$ Stevens et al. ${ }^{22}$ studied the effect of the initial lower-extremity posture, including foot posture, on the STS movement, and they reported that the preferred lower-extremity position leads to less head movement and lower ground reaction forces. It was supposed that the condition with the affected foot moved considerably back reduced the asymmetry of the vertical reaction forces between the lower limbs $11 \%$ more than the non-affected foot back or the symmetrical foot position in the sit-to-stand task, and they recommended the sit-to-stand movement with the affected foot back when performing symmetrical sit-to-stand posture with patients with hemiparesis. ${ }^{23}$ A symmetrical weight-bearing pattern in both limbs has been demonstrated when patients conducted back-to-sit movements with the affected foot back rather than with the feet in a symmetrical position. ${ }^{24}$ This is quite similar to the results of our study, by comparison with also previous another study suggested only once measurement outcome, the results of our study are considered to be the effects of the motor learning due to the training.

On the other hand, Duclos et al. ${ }^{25}$ reported that in hemiparetic individuals, improving sit-to-stand symmetry by positioning the affected foot behind the non-affected foot did not increase medio- lateral stability, which was associated with the level of stroke-related motor impairments.

Limb-loading asymmetry may also develop during recovery to reduce the risk of falling toward the affected limb by compensating for the muscle weakness and impaired sensory awareness in the affected limb. The advantages of sit-to-stand training with greater loading on the affected limb may include increased muscle strength and increased confidence in placing weight on the affected limb by maximizing joint compression and extending the sensory awareness of the limb. Another potential benefit is that greater attention to the affected limb may alter the effects of learned non-use. ${ }^{26}$

This study found that the asymmetrical group showed a significant increase in static and dynamic balance in comparison to the spontaneous group after repetitive sit-to-stand training. Based on this result, it is clear that training in an asymmetrical position with the paretic foot back increased the medio-lateral stability limit and the anterior-posterior stability limit, which improved balance control. The results of this study suggest that repetitive sit-to-stand training with the paretic foot back influences balance in chronic stroke subjects. If this training is combined with conventional neurologic physiotherapy, it could be an effective training method for increasing the balance and weight-bearing ability of stroke patients.

\section{REFERENCES}

1. Peurala SH, Kononen P, Pitkanen K, et al. Postural instability in patients with chronic stroke. Restor Neurol Neurosci. 2007;25(2):101-8.

2. Lee KS, Kim CS. The effect of medio-lateral balance to head rotation in stroke patient. J Korean Soc Phys Ther. 2012;24(5):334-9.

3. Jung KS, Chung YJ. The effect of changes in walking aids on weight bearing on the cane and foot in stroke. J Korean Soc Phys Ther. 2012; 24(2):113-7.

4. Kusoffsky A, Apel I, Hirschfeld H. Reaching-lifting-placing task during 
standing after stroke: Coordination among ground forces, ankle muscle activity, and hand movement. Arch Phys Med Rehabil. 2001;82(5):650-60.

5. Turnbull GI, Charteris J, Wall JC. Deficiencies in standing weight shifts by ambulant hemiplegic subjects. Arch Phys Med Rehabil. 1996;77(4): 356-62.

6. Lee SY, Lee MH, Park MC, et al. The effects the type of canes handle affects in recovering-balance of hemiplegic patients. . J Korean Soc Phys Ther. 2008;20(4):7-14

7. Lee SW, In TS, et al. Immediate effects of load stimulation on static balance and muscle activities in chronic stroke patients. J Korean Soc Phys Ther. 2009;21(1):19-26.

8. Engberg W, Lind A, Linder A, et al. Balance-related efficacy compared with balance function in patients with acute stroke. Physiother Theory Pract. 2008;24(2):105-11.

9. Malouin F, Richards CL, Doyon J, et al. Training mobility tasks after stroke with combined mental and physical practice: A feasibility study. Neurorehabil Neural Repair. 2004;18(2):66-75.

10. Hesse S, Bertelt C, Schaffrin A, et al. Restoration of gait in nonambulatory hemiparetic patients by treadmill training with partial body-weight support. Arch Phys Med Rehabil. 1994;75(10):1087-93.

11. Cheng PT, Liaw MY, Wong MK, et al. The sit-to-stand movement in stroke patients and its correlation with falling. Arch Phys Med Rehabil 1998;79(9):1043-6.

12. Eng JJ, Chu KS. Reliability and comparison of weight-bearing ability during standing tasks for individuals with chronic stroke. Arch Phys Med Rehabil. 2002;83(8):1138-44.

13. Brunt D, Greenberg B, Wankadia S, et al. The effect of foot placement on sit to stand in healthy young subjects and patients with hemiplegia. Arch Phys Med Rehabil. 2002;83(7):924-9.

14. Cheng PT, Wu SH, Liaw MY, et al. Symmetrical body-weight distribution training in stroke patients and its effect on fall prevention. Arch Phys Med Rehabil. 2001;82(12):1650-4.

15. Podsiadlo D, Richardson S. The timed "up \& go": A test of basic functional mobility for frail elderly persons. J Am Geriatr Soc. 1991;39(2): 142-8.
16. Morris S, Morris ME, Iansek R. Reliability of measurements obtained with the timed "up \& go" test in people with parkinson disease. Phys Ther. 2001;81(2):810-8.

17. Lord SR, Murray SM, Chapman K, et al. Sit-to-stand performance depends on sensation, speed, balance, and psychological status in addition to strength in older people. J Gerontol A Biol Sci Med Sci. 2002;57(8): M539-43.

18. Duncan PW, Weiner DK, Chandler J, et al. Functional reach: A new clinical measure of balance. J Gerontol. 1990;45(6):M192-7.

19. Roy G, Nadeau S, Gravel D, et al. Side difference in the hip and knee joint moments during sit-to-stand and stand-to-sit tasks in individuals with hemiparesis. Clin Biomech (Bristol, Avon). 2007;22(7):795-804.

20. Rocha Ade S, Knabben RJ, Michaelsen SM. Non-paretic lower limb constraint with a step decreases the asymmetry of vertical forces during sit-to-stand at two seat heights in subjects with hemiparesis. Gait Posture. 2010;32(4):457-63.

21. Kawagoe S, Tajima N, Chosa E. Biomechanical analysis of effects of foot placement with varying chair height on the motion of standing up. J Orthop Sci. 2000;5(2):124-33.

22. Stevens C, Bojsen-Moller F, Soames RW. The influence of initial posture on the sit-to-stand movement. Eur J Appl Physiol Occup Physiol. 1989;58(7):687-92.

23. Roy G, Nadeau S, Gravel D, et al. The effect of foot position and chair height on the asymmetry of vertical forces during sit-to-stand and standto-sit tasks in individuals with hemiparesis. Clin Biomech (Bristol, Avon). 2006;21(6):585-93.

24. Yang YR, Chen IH, Liao KK, et al. Cortical reorganization induced by body weight-supported treadmill training in patients with hemiparesis of different stroke durations. Arch Phys Med Rehabil. 2010;91(4):513-8.

25. Duclos C, Nadeau S, Lecours J. Lateral trunk displacement and stability during sit-to-stand transfer in relation to foot placement in patients with hemiparesis. Neurorehabil Neural Repair. 2008;22(6):715-22.

26. Gray CK, Culham E. Sit-to-stand in people with stroke: Effect of lower limb constraint-induced movement strategies. Stroke Res Treat. 2014; Article ID 683681:1-8. 